\title{
The Application of Digital Media Technology in the Training of Animation and Photography Talents
}

\author{
Yanqing Cui \\ Shandong Binzhou University, Shandong, China, 256600
}

Keywords: Digital media technology; animation; photography; personnel training

Abstract: With the development of science and information technology, digital media technology has been widely used in people's life and work. It has been developed rapidly in China. More and more digital media companies have been set up. The main feature of digital media is the integration of high technology and culture. However, influenced by the situation of our country, the professionals of mathematical media technology are far from meeting the needs of industry. The demand for development, especially the serious shortage of high-end talents in digital media technology, is one of the main reasons hindering the development of digital media industry. Therefore, this paper studies the application of digital media technology in the training of animation and photography talents.

With the continuous improvement of China's economic level, the animation industry has also achieved rapid development. The development of animation can not be separated from the application of digital media technology. Digital media technology is an application technology based on information multimedia technology. It plays an important role in animation design and production. It can not only be used in the design of scenes, the design of characters and post-processing, but also in the comprehensive processing of text, graphics, sound and video. It is an indispensable important technology for the development of animation industry. Therefore, we must attach great importance to the application of digital media technology in the training of animation and photography talents.

\section{Definition of Digital Media Technology}

Digital media technology is mainly based on Information Science and digital technology. According to the basic theory of mass communication, science and technology are highly integrated with culture and art, and information communication technology is applied to culture, art, education and other fields. It can be seen that the application of mathematical information technology is very extensive, and it is a comprehensive interdisciplinary rising in modern times. As shown in figure 1. 


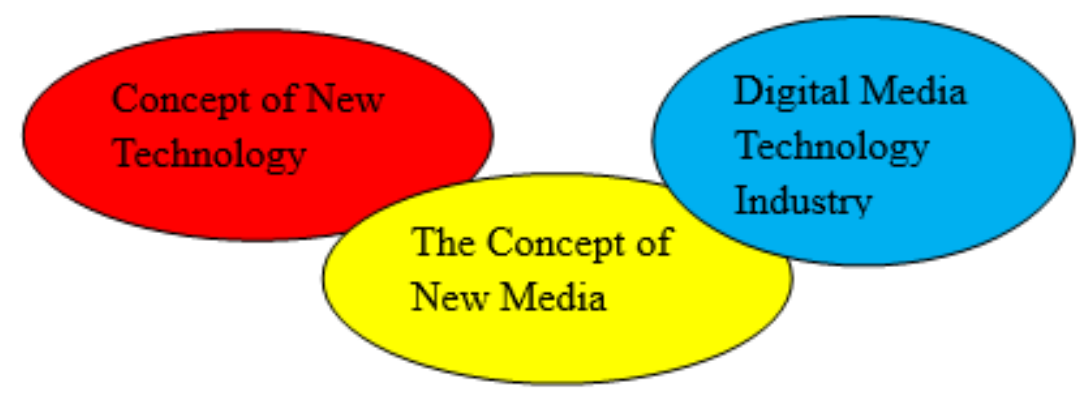

Figure 1. Definition of Digital Media Technology

\subsection{Concept of New Technology}

Digital media technology mainly relies on the use of modern computer and information dissemination means to transform abstract words, sounds and pictures into a modern information technology that can be perceived and interacted. Digital media technology also includes computer technology, network and communication technology, information processing technology and other integrated application technologies. The key technologies include digital information acquisition and output technology, digital information processing technology and digital communication technology. Computer animation technology and virtual reality technology belong to other comprehensive technologies.

\subsection{The Concept of New Media}

Digital media technology is a new type of information technology, which is rising in recent years. It can obtain information such as text, image, video and audio, virtual reality, and record, process, process, disseminate and manage these information, such as digital newspapers and magazines, digital movies and television. Traditionally, the media are mainly newspapers, outdoors, radio and television, so people call digital media technology "the fifth media".

\subsection{Digital Media Technology Industry}

The application of digital media technology is relatively extensive, so more and more digital media companies have been set up to promote the formation of digital media technology industry, mainly through the application of digital technology, network technology and multimedia technology, to provide digital cultural products for the society. Digital media technology industry mainly includes: design, advertising, photography, film, television, music, animation, games, visual arts, information services and so on. Under the trend of economic globalization, all countries in the world attach great importance to the application of digital media technology, focus on supporting the digital media technology industry, and recommend the development of digital media technology industry in an all-round way.

\section{Talent Demand of Animation Market}

As shown in figure 2. The flourishing development of digital media industry urgently needs a large number of professional talents, especially those who have both theoretical basis and artistic accomplishment, and strong practical ability. According to a survey data, digital media talents have become popular in the market in recent years, with an annual increase of $25 \%$ in quantity demand and $34 \%$ in salary. Experts predict that in the next three to five years, China's digital media 
technology talent gap will reach as many as 1 million people.

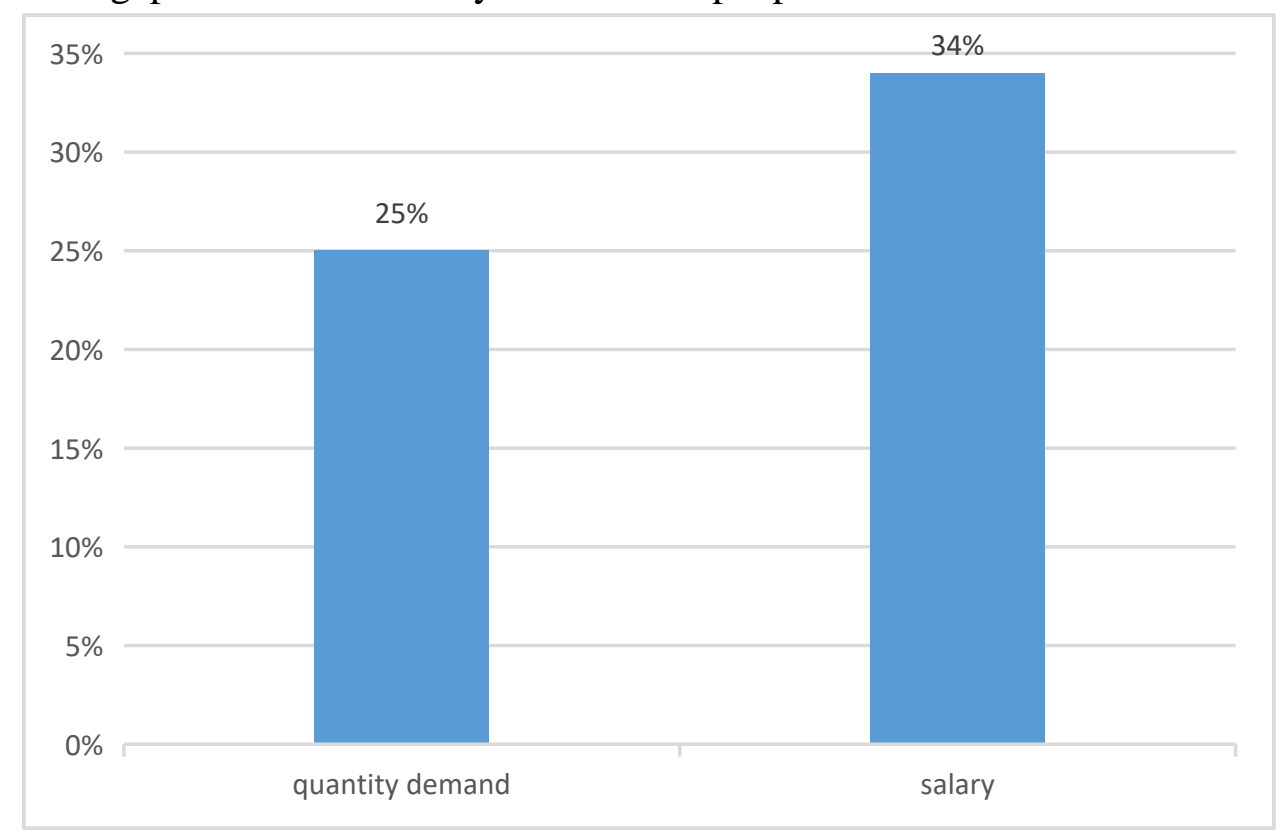

Figure 2. Talent Demand of Animation Market

\subsection{Quantity Demand of Animation Talents}

China's animation industry is in a period of rapid development, the industry plays an increasingly important role in China's cultural industry, Animation talent is extremely scarce, technology is too hard, experienced composite talents will be difficult to demand, but also in art, film and television, design, music and marketing, etc. Are proficient. But the reality is that the national animation practitioners are still far from meeting the demand for talent in the domestic animation industry. Therefore, the animation industry needs a lot of time, more manpower and material resources. At the same time, the animation industry covers a wide range of areas, and the industrial chain is also long, requiring multi-user talents.

\subsection{Ability Demand of Animation Talents}

At present, the shortage of talents in the animation industry mainly concentrates on the following six categories: story creation, two-dimensional and three-dimensional animation production, animation software development, network and mobile game development, animation product design and marketing. At present, animation talents are mainly needed by film and television companies, animation companies, digital information companies, game companies and so on. Through actual research and development, it is found that the demand for two-dimensional animation talents has begun to decrease significantly, while the demand for three-dimensional animation talents has increased significantly.

\section{Specific measures to promote the application of digital media technology in the training of} animation and photography talents

In order to promote the application of digital media technology in animation design and production, and promote the further development of animation, we must take effective measures, such as human-centered, science and technology as a supplement to the development of animation, 
adhere to Chinese characteristics, draw appropriate lessons from foreign excellent works, train excellent animation talents and increase the research and development of digital media technology, etc. The specific analysis is as follows.

\subsection{Develop animation based on Humanities and supplemented by science and technology}

To further promote the long-term development of China's animation, we can not only rely on science and technology to design and produce animation, otherwise it will only attract the public's attention in the short term. In the long run, the public will be aesthetic fatigue, will lose patience with animation, which is not conducive to the development of China's animation. Therefore, we should develop animation based on Humanities and supplemented by scientific and technological means. For example, we can inject more traditional cultural elements into animation, balance the commercial value and artistic value of animation, so that animation can really achieve long-term development.

\subsection{Adhering to Chinese Characteristics and Drawing Appropriately on Excellent Works from Foreign Countries}

China's animation development is slightly behind many countries, it can not be denied that many countries have a good development in animation, but we can not blindly copy foreign animation works, but should adhere to Chinese characteristics, appropriate use of foreign excellent works to develop China's animation industry. This requires us to make full use of digital media technology on the basis of the animation into China's characteristic culture, and appropriate use of some other intercommunication inspiration for animation design and production. For example, the character of the monkey in Aeolian Lantern has Chinese characteristics, and its shape borrows from the image of Hollywood, which is an organic combination of foreign and Chinese characteristics of animation performance.

\subsection{Training Excellent Animation Talents}

In order to promote the application of digital media technology in animation design and production, people are the main executors, and excellent talents are the foundation. Therefore, we should pay attention to training excellent animation talents. This requires us to start with education, cultivate a group of excellent animation design students, and let these students deeply master the use of digital media technology, but also pay attention to training characteristically ability. In addition, we should also increase investment in talents, and introduce some excellent talents from abroad, so that these talents can escort the development of China's animation industry and promote the long-term development of China's animation.

\section{Conclusion}

In a word, the application of digital media technology in the training of animation photography talents can not only improve the quality of animation creation, but also effectively improve the efficiency of animation creation, which is an important topic worthy of our great attention. This requires us to continue to explore in practice with the most scientific spirit, the most rigorous attitude and the most professional level, and to develop effective measures to promote digital media technology to play a greater role in animation design and production. I believe that through our unremitting efforts, we can certainly promote the long-term development of China's animation. 


\section{References}

[1] Angelia Yuan. On the influence of digital media in animation design [J]. Computer fans, 2017, (12): 200.

[2] Chou Deng, Li Guiyang. Innovative application of digital media art in animation design [J]. Art Science and Technology, 2017, (10): 144.

[3] Ye Fun, Pan Fanning, Bhang Fan. Discussion on the Training of Compound Digital Media Technology Professionals [J]. Press, 2009 (4).

[4] Ciao Hongi, Chen Bu. Exploration and Practice of Digital Media Technology Professional Training [J]. Science and Technology Information, 2012 (33).

[5] Ca Translated. Analysis and Exploration of the Current Situation of Digital Media Professional Training [J]. Journal of Reckoning Radio and Television University, 2015 (2). 